\title{
Population Age Structure, Social Security and Household consumption rate
}

\author{
Xiulin $\mathrm{Ji}^{1, \mathrm{a}}$ Meixia Shi ${ }^{1, \mathrm{~b}}$ \\ ${ }^{1}$ School of Economics and Management Beijing Jiaotong University Beijing, China
}

\begin{abstract}
This paper uses panel data from 31 provinces in China from 2005 to 2018, and examines the relationship between the age structure of the population, the level of social security, and the consumption rate of residents by establishing static and dynamic models. The study found that, the child dependency ratio and the elderly dependency ratio have a negative impact on the residents' consumption rate. Child dependency ratio increased by $1 \%$, resident consumption rate decreased by $7.4 \%$. Elderly dependency ratio increased by $1 \%$, resident consumption rate decreased by $13.7 \%$. Pension coverage has no significant impact on household consumption rates. Moreover, the consumption of Chinese residents is inertia, that is, the current consumption of residents is affected by previous consumption habits, which is one of the reasons for the current low consumption rate of our residents. In addition, research shows that the per capita real GDP and real interest rate promote China's residents' consumption, and the inflation rate and urbanization level have a certain inhibitory effect on the residents' consumption rate. Therefore, the development of distinctive children's training courses and the elderly-related industries, the optimization of the elderly's labor market, and the gradual change of residents' consumption concepts are more effective ways to expand domestic demand.
\end{abstract}

\section{INTRODUCTION}

Since the reform and opening up, China's rapid economic development is obvious to all. Although it has slowed down in recent years, it has remained above $6 \%$. On the contrary, the proportion of household consumption in GDP has always been at a low level. According to the statistics of the World Bank, the consumption rate of Chinese residents in 2017 was $38.4 \%$, far lower than that of India (58.9\%), Egypt $(86.8 \%)$, the United Kingdom (65.7\%) and Russia (52.4\%). The consumption rate of residents in other countries ranks 33rd among 36 countries. In addition, from 1990 to 2017, China's household consumption rate fell by 9.4 percentage points, an average annual decrease of $0.35 \%$.

Uneven income distribution (Yuan Zhigang, Zhu Guolin,2002), residents' consumption inertia (Li Wenxing, $\mathrm{Xu}$ Changsheng, etc., 2008), the stimulating effect of urbanization on consumption has not been fully reflected (Fu Bohang, Wan Qiyun,etc.,2013), uncertainty about future income and expenditure (Luo Chuliang,2004) and so on are all reasons for insufficient domestic demand. Yuan Zhigang and Song Zheng (2000) believe that the income path and consumption behavior of Chinese residents will change to some extent due to changes in the age structure of the population. The existing literature has different views on the effect of social security level and population age structure on residents' consumption. Some scholars believe that there is a positive effect, some scholars believe that it is a negative effect, and some scholars believe that there is no significant effect between the two. Therefore, this paper uses China's provincial panel data for analysis to further inform the relationship between China's population age structure, social security and residents' consumption with a view to providing a reference for future economic policy formulation.

\section{MeAsurement model AND dATA DESCRIPTION}

\section{A. Econometric Model}

Drawing on the existing research by $\mathrm{Li}$ Wenxing(2008), this article selects a simple consumption model. The model divides the independent variables into: basic variable $X$, attention variable (including population structure variable $\mathrm{Y}$ and social security variable PEN), and control variable $Z$. The established panel model is shown in equation (1).

$\mathrm{CON}_{\mathrm{it}}=\alpha_{0}+\beta_{1} X+\beta_{2} Y+\beta_{3} P E N+\beta_{4} Z+u_{\mathrm{i}}+v_{\mathrm{it}}$

In this model, the $\mathrm{i}$ represents the province, $\mathrm{t}$ represents time, $u_{i}$ is an unobservable regional effect, $v_{i t}$ is a random disturbance term, and the dependent variable $\mathrm{CON}$ is the household consumption rate. That is, the proportion of household consumption expenditure to GDP in the expenditure method.

axiulin_ji@163.com bmxshi@bjtu.edu.cn 
Basic variable $\mathrm{X}$, including real income and real interest rate (R). Real income uses the logarithm of real GDP per capita (LNGDP) in each region as a proxy variable; the real interest rate affects consumers' intertemporal choices.

The age structure variable $\mathrm{Y}$ of the population is measured by the child dependency ratio (CDR) and the elderly dependency ratio (ODR). The social security level variable $(\mathrm{PEN})$ is expressed by the coverage of pension insurance (Cover), which is measured by the ratio of the number of pension insurance participants in each province to the total population of urban residents. In addition, two interaction variables (CDR*Cover) for children's dependency ratio and endowment insurance coverage (ODR* Cover) for old-age dependency ratio and pension coverage are added to the model.

This paper considers other important variables that have an impact on household consumption, including inflation rate (INF), urban-rural income gap (RUI) and urbanization level (UR). The urban-rural income gap (RUI) is expressed as the ratio of per capita net income of urban and rural households. The urbanization level (UR) is expressed as the proportion of urban population in the total population in each region. From this, the following extended model (2) can be obtained.

$$
\begin{aligned}
& C O N_{i t}=\alpha_{0}+\beta_{1} L N G D P+\beta_{2} R+\beta_{3} C D R+\beta_{4} \text { ODR } \\
& +\beta_{5} \text { Cover }+\beta_{6} \text { CDRCover }+\beta_{7} \text { ODRCover }+\beta_{8} I N F \\
& +\beta_{9} R U I+\beta_{10} U R+u_{i}+v_{i t}
\end{aligned}
$$

In addition, considering that residents' consumption has a certain consumption inertia ( $\mathrm{Li}$ Wenxing et al., 2008), a lagging period of the dependent variable's consumption rate is introduced as a proxy variable for residents' consumption habits in the model. From this, equation (3) can be obtained.

$$
\begin{aligned}
& C O N_{i t}=\alpha_{0}+\beta_{0} C O N_{i(t-1)}+\beta_{1} L N G D P+\beta_{2} R+\beta_{3} C D R \\
& +\beta_{4} \text { ODR }+\beta_{5} \text { Cover }+\beta_{6} C D R \text { Cover }+\beta_{7} \text { ODRCover }+ \\
& \beta_{8} I N F+\beta_{9} R U I+\beta_{10} U R+u_{i}+v_{i t}
\end{aligned}
$$

\section{B. Data}

This paper uses the provincial panel data of 31 provinces in mainland China. The sample period is from 2005 to 2018.In order to eliminate the impact of inflation, the real GDP per capita has been adjusted to 2005 as the base period. The original data are from the National Bureau of Statistics.

\section{EMPIRICAL ANALYSIS}

In order to avoid the problem of pseudo-regression, the stationarity test is done before the regression. This article uses LLC test, IPS test, HT test and ADF test respectively. According to the stationarity test results in Table Iand II, the resident consumption rate, logarithm of real per capita GDP (LNGDP), real interest rate, inflation rate, urbanrural income gap, and urbanization rate all reject the original hypothesis. That is, the data is stable. Resident consumption rate lagged one period, children's dependency ratio, old-age dependency ratio, old-age insurance coverage rate, interactive terms for children's dependency ratio and pension insurance coverage rate, old-age dependency ratio and pension insurance coverage rate interaction terms all met "at least two tests refused to exist the original hypothesis of unit root ". So all variables have passed the stationarity test.

\section{A. Static Model Estimation Results}

According to the estimation results of the basic model, it is found that the child dependency ratio, the elderly dependency ratio and the pension insurance coverage rate have a significant positive effect on the residents' consumption rate. From the estimated results of this simple model, it is well in line with the expectations of the life cycle hypothesis model.

TABLE I. STATIONARITY TEST RESUltS

\begin{tabular}{|l|l|l|l|l|}
\hline \multirow{2}{*}{ Variable } & \multicolumn{2}{c|}{ LLC } & \multicolumn{2}{c|}{ IPS } \\
\cline { 2 - 5 } CON & \multicolumn{1}{c|}{ Statistics } & \multicolumn{1}{c|}{$\boldsymbol{P}$} & \multicolumn{1}{c|}{ Statistics } & \multicolumn{1}{c|}{} \\
\hline CON(-1) & -4.5337 & 0.0000 & -2.6443 & 0.0041 \\
\hline LNGDP & -2.5866 & 0.0048 & 3.7719 & 0.9999 \\
\hline R & -9.1478 & 0.0000 & -7.5890 & 0.0000 \\
\hline CDR & -2.4083 & 0.0080 & -3.2643 & 0.0005 \\
\hline ODR & -6.2963 & 0.0000 & -0.7573 & 0.2244 \\
\hline Cover & -22.8771 & 0.0000 & 1.0413 & 0.8511 \\
\hline CDR*Cover & -2.9518 & 0.0016 & -1.7991 & 0.0360 \\
\hline ODR*Cover & -2.8189 & 0.0000 & -0.4487 & 0.3268 \\
\hline INF & -2.4080 & 0.0080 & -3.2642 & 0.0005 \\
\hline RUI & -2.8196 & 0.0024 & -6.4349 & 0.0000 \\
\hline UR & -9.9451 & 0.0000 & -7.3774 & 0.0000 \\
\hline
\end{tabular}

TABLE II. STATIONARITY TEST RESULTS

\begin{tabular}{|l|l|l|l|c|}
\hline \multirow{2}{*}{ Variable } & \multicolumn{2}{c|}{ HT } & \multicolumn{2}{c|}{ ADF } \\
\cline { 2 - 5 } & Statistics & \multicolumn{1}{c|}{$\boldsymbol{P}$} & Statistics & $\boldsymbol{P}$ \\
\hline CON & -3.6435 & 0.0001 & -3.5436 & 0.0002 \\
\hline CON(-1) & -3.1617 & 0.0008 & -3.8434 & 0.0001 \\
\hline LNGDP & -1.6978 & 0.0448 & -2.2551 & 0.0121 \\
\hline R & -10.0893 & 0.0000 & -2.7741 & 0.0028 \\
\hline CDR & -4.7701 & 0.0000 & -6.7468 & 0.0000 \\
\hline ODR & -2.1868 & 0.0144 & -4.5439 & 0.0000 \\
\hline Cover & 0.9652 & 0.8328 & -6.1678 & 0.0000 \\
\hline CDR*Cover & -1.1292 & 0.1294 & -6.3770 & 0.0000 \\
\hline ODR*Cover & -0.3334 & 0.3694 & -2.0787 & 0.0188 \\
\hline INF & -10.0893 & 0.0000 & -2.7740 & 0.0028 \\
\hline RUI & -2.8487 & 0.0022 & -6.7552 & 0.0000 \\
\hline UR & -10.4139 & 0.0000 & -7.3724 & 0.0000 \\
\hline
\end{tabular}

a. The table results are obtained through stata 12 
The columns 2 and 3 in Table III are the estimation results obtained according to equation (2), and $\mathrm{FE}$ is selected according to the Hausman value. The sign of the children's dependency ratio, old-age dependency ratio and pension insurance coverage is the same as the basic model. And LNGDP and real interest rate have a significant negative impact on the residents' consumption rate. Urbanization is conducive to promoting residents' consumption. For every $1 \%$ increase in the level of urbanization, the consumption rate of residents will increase by $0.05 \%$. In addition, the coefficients of the interaction terms of the children's dependency ratio and the pension insurance coverage rate, and the interaction terms of the elderly dependency ratio and the pension insurance coverage rate are significantly negative, indicating that the increase of the children's dependency ratio and the elderly dependency ratio will weaken the promotion of pension insurance to residents' consumption effect.

\section{B. Dynamic Model Estimation Results}

Equation (3) adds proxy variables of consumption habits. In order to overcome the possible autocorrelation problems, endogenous problems, missing variables, and measurement errors among variables. This paper further establishes a dynamic panel GMM model to analyze the relationship between population age structure, pension insurance coverage and residents' consumption. One-step estimator is inefficient compared to two-step estimator, but it is consistent. There is also evidence that the system GMM has less deviation and higher efficiency than the differential GMM estimation (Blundell and Bond, 2000). Therefore, the dynamic panel model in this paper uses a one-step system GMM estimation. The estimated results are shown in the last column of Table III.

The AR value in the table shows that there is no residual second-order autocorrelation problem. And the Hansen test is 0.938 , which does not reject the null hypothesis that the instrument variable is valid. Which indicates that the one-step system GMM regression results do not have excessive recognition problems. Therefore, the one-step system GMM estimation method is effective, and the empirical results can be analyzed.

The coefficient of resident consumption rate lagging one period is significantly positive, verifying that people's consumption has a certain inertia. That is, the current consumption is affected by previous consumption habits.

The coefficient sign of the child dependency ratio and the elderly dependency ratio is opposite to the static model. The child dependency ratio increases by $1 \%$ and the resident consumption rate decreases by $7.4 \%$. The elderly dependency ratio increases by $1 \%$ and the resident consumption rate decreases by $13.7 \%$. The reason may be that the static model does not consider consumption habits, that is, the static model has missing important variables. The decrease in the number of child-rearing, changes in the concept of child-rearing, and changes in educational concepts have made parents pay more attention to investment in child human capital. As a result, a lower child rearing ratio has led to an increase in resident consumption. This conclusion is consistent with China's national conditions. China has entered an aging society. With the increase of the elderly population, the future per capita disposable income will decrease, which will have a certain inhibitory effect on consumption growth. And the concept of helping children's family life makes their consumption desire lower and consumption behavior more cautious. Therefore, the increase of the old-age dependency ratio will inhibit the growth of the residents' consumption rate.

TABLE III. ESTIMATION RESULTS FOR STATIC AND DYNAMIC MODELS

\begin{tabular}{|c|c|c|c|}
\hline \multirow{2}{*}{ Variables } & \multicolumn{2}{|c|}{ Extended model } & \multirow{2}{*}{$\begin{array}{c}\text { One-step } \\
\text { GMM }\end{array}$} \\
\hline & Fixed effect & Random effect & \\
\hline $\mathrm{CON}(-1)$ & & & $\begin{array}{l}1.073 * * * \\
(0.043)\end{array}$ \\
\hline LNGDP & $\begin{array}{c}-2.175^{* * *} \\
(0.578)\end{array}$ & $\begin{array}{c}-2.802 * * * \\
(0.638)\end{array}$ & $\begin{array}{r}2.016 * * * \\
(0.465)\end{array}$ \\
\hline CDR & $\begin{array}{r}0.864 * * * \\
(0.107)\end{array}$ & $\begin{array}{r}0.789 * * * \\
(0.111)\end{array}$ & $\begin{array}{r}-0.074^{*} \\
(0.039)\end{array}$ \\
\hline ODR & $\begin{array}{r}1.227 * * * \\
(0.250)\end{array}$ & $\begin{array}{r}1.087 * * * \\
(0.262)\end{array}$ & $\begin{array}{r}-0.137 * \\
(0.073)\end{array}$ \\
\hline Cover & $\begin{array}{r}0.760 * * * \\
(0.093)\end{array}$ & $\begin{array}{r}0.766 * * * \\
(0.095)\end{array}$ & $\begin{array}{r}-0.029 \\
(0.018)\end{array}$ \\
\hline $\mathrm{R}$ & $\begin{array}{c}-1.972 * * * \\
(0.319) \\
\end{array}$ & $\begin{array}{c}-1.962 * * * \\
(0.314) \\
\end{array}$ & $\begin{array}{r}0.701 * * * \\
(0.192) \\
\end{array}$ \\
\hline CDR*Cover & $\begin{array}{c}-1.900 * * * \\
(0.269)\end{array}$ & $\begin{array}{c}-2.086^{* * * *} \\
(0.288)\end{array}$ & $\begin{array}{l}-0.0007 \\
(0.0006)\end{array}$ \\
\hline ODR*Cover & $\begin{array}{r}-1.926^{* * *} \\
(0.473)\end{array}$ & $\begin{array}{c}-1.644 * * * \\
(0.474)\end{array}$ & $\begin{array}{l}0.0013 \\
(0.0012)\end{array}$ \\
\hline INF & $\begin{array}{r}-0.0124 \\
(0.084)\end{array}$ & $-0.027(0.081)$ & $\begin{array}{c}-0.371 * * * \\
(0.043)\end{array}$ \\
\hline RUI & $\begin{array}{l}0.332 \\
(0.562)\end{array}$ & $-0.222(0.573)$ & $\begin{array}{l}-0.394 \\
(0.252)\end{array}$ \\
\hline UR & $\begin{array}{l}0.028 \\
(0.029)\end{array}$ & $0.052 *(0.031)$ & $\begin{array}{c}-0.049^{* * *} \\
(0.016)\end{array}$ \\
\hline Constant & $\begin{array}{c}21.188 * * * \\
(1.982)\end{array}$ & $\begin{array}{l}31.580 * * * \\
(8.388)\end{array}$ & $\begin{array}{c}-16.380 * * * \\
(5.709)\end{array}$ \\
\hline Hausman & & 0.0326 & \\
\hline F statistic & 305 & & \\
\hline R2 in group & 0.4223 & 0.4313 & \\
\hline Group R2 & 0.4993 & 0.2004 & \\
\hline Overall R2 & 0.4338 & 0.2721 & \\
\hline $\mathrm{AR}(1)$ & & & 0.001 \\
\hline $\mathrm{AR}(2)$ & & & 0.438 \\
\hline Hansen & & & 0.938 \\
\hline
\end{tabular}

a. $*, * *, * * *$ significant at $10 \%, 5 \%$ and $1 \%$ levels respectively

Pension insurance coverage has a negative impact on residents' consumption rate, but it is not significant in the one-step system GMM estimation, that is, the impact of pension insurance coverage on residents' consumption rate is uncertain. On the one hand, with the improvement of the pension insurance system and the improvement of the pension insurance coverage, the future uncertainty of residents has been reduced, which will reduce preventive savings to a certain extent and increase current consumption. On the other hand, the issuance of basic old-age insurance funds is premised on payment during working hours, which results in a reduction in residents' current income and causes residents to reduce current consumption. 
The urbanization rate has a significant negative impact on residents' consumption. There are two main reasons. First, the congestion cost caused by the urbanization agglomeration effect lags behind the growth of output. And second, the urban consumption level is higher than that of the rural population. When moving to cities and towns, in order to reach the city's consumption level, a saving behavior may be carried out for a period of time, which will cause a decline in the residents' consumption rate. In the dynamic model, the interaction terms of urbanrural income gap, child dependency ratio and pension insurance coverage have a negative impact on residents' consumption rate. The interaction terms of elderly dependency ratio and pension insurance have a positive effect on residents' consumption rate, but none of them pass the significance test. For other variables, the coefficients before real income, real interest rate, and inflation rate were $2.016,0.701$, and -0.371 , respectively, and all passed the significance test. That is, real income and real interest rate have a certain promotion effect on China's resident consumption, and inflation rate has a certain restraining effect on the resident consumption rate.

\section{CONCLUSION AND SUGgESTION}

Based on the provincial panel data of 31 provinces in mainland China from 2005 to 2018, this paper established a one-step system GMM estimation and found that, children's dependency ratio, elderly dependency ratio and residents' consumption rate all have significant negative effects, while pension insurance coverage has no significant impact on the consumption rate of residents. In addition, China's residents' consumption is inertial, that is, the residents' consumption in the current period is affected by the residents' previous consumption habits. In addition, China's resident consumption is also affected by the logarithm of real GDP per capita, real interest rate, inflation rate, and urbanization rate.

At present, China has entered an aging society, and the old-age dependency ratio continues to rise, resulting in a continuous decline in the consumption rate of residents. Childrenization brings a drop in the dependency ratio of children, leading to an increase in residents' consumption levels. However, from the perspective of model coefficients, the latter is much lower than the former. The increase in the household consumption rate caused by the decrease in the child dependency ratio is much lower than the decrease in the household consumption level caused by the increase in the elderly dependency ratio. From this research point of view, the increase in the elderly dependency ratio in recent years can be used as one of the reasons for insufficient domestic consumption at this stage. In addition, the main reason affecting the consumption level of residents in China is the inertia of residents' consumption. Therefore, the fine tradition of frugality in China and the prudent consumption concept are also one of the reasons for the low consumption rate of Chinese residents. China's empirical data from 2005 to 2018 shows that the reduction in household consumption is affected by the increase in pension insurance coverage, but it has not passed the significance test.
Based on the above main conclusions, the author puts forward the following suggestions for the low consumption rate of Chinese residents.

First, to create an environment where the old people can enter the labor market again, in which the talented people with innovative talents who still have employment demands or knowledge and ability. For example, reemployment of senior teachers and doctors.

Second, in a population environment where both children and the elderly may increase. On the one hand, we must focus on strengthening investment in children's human capital, and develop special education and training courses or activities for children, so as to stimulate domestic consumption. On the other hand, we should continue to improve the social security system for the elderly and reduce residents' uncertainty about the future. At the same time, we must actively develop the leisure and entertainment industry for the elderly and develop an attractive consumer market, thereby stimulating the consumer demand for the elderly.

Third, take some measures to reduce the barriers of the urban and rural household registration system, and encourage the surplus rural labor to move to cities. At the same time, the support of the social management system should be strengthened to enable non-urban population to enjoy basic rights and interests in the city, so that they can consume and dare to consume.

\section{REFERENCES}

1. Z.G. Yuan, and G.L. Zhu. Income Distribution and Total Consumption in Consumption Theory -- Analysis of China's Sluggish J. Clerk Maxwell, A Treatise on Electricity and Magnetism, 3rd ed., vol. 2. Oxford: Clarendon, 1892, pp.68-73.

2. W.X. Li,C.S. Xu, and C.R. Ai.Age Structure and Household Consumption in China :1989 -- 2004[J].Economic Research,2008(07):118-129.

3. B.H. Fu,Q.Y. Fang, and D.Y. Song. Urbanization, Population Age Structure and Resident Consumption: An Empirical Study Based on The Inter-Provincial Dynamic Panel [J]. China Population Resources and Environment,2013,23(11):108-114.

4. C.L. Luo. Economic Transition, Uncertainty and Consumption Behavior of Urban Residents [J]. Economic Research,2004(04):100-106.

5. Z.G. Yuan, Z.Song. Age Structure of Population, Endowment Insurance System and Optimal Savings Rate [J]. Economic Research,2000(11):24-32+79

6. H.E. Leland.Saving and Uncertainty : the Precautionary Demand for Savings, Quarterly Journal of Economics, 1968 (82) : 465- 473 .

7. J.H. Shen. Effect of Age Structure of Population on Consumption Rate -- Empirical Analysis Based on Panel Data of Chinese Provinces [J]. Shanghai Economic Research,2015(04):36-41.

8. National Bureau of Statistics of The People's Republic of China. China Statistical Yearbook [M]. Beijing: China Statistics Press, 2005-2019.

9. X.Q. Hou. Research on Income Threshold Effect of Social Endowment Insurance on Residents' Consumption [J]. Consumer Economy,2019,35(02):34-42.

10. Z.Li, Q.Zhao. Does China's Urban Endowment Insurance System Squeeze Into Residents' Consumption? -Analysis of Time Series and Panel Data Based on Cities and Towns [J]. Journal of Public Administration, 2015,12(04):102-110+158 
11. M.Feldstein. Social Security and Saving : The Extended Life Cycle Theory[J]. American Economic Association, 1974, 66(2) : 77- 86.

12. Z.G. Wang.Panel Data Model and Its Application in Economic Analysis [M].Beijing:Economic Science Press,2008:59-62.
13. R.W. Blundell,S.R. Bond.GMM Estimation With Persistent Panel Data;An Application to Production Functions [J].Economic Reviews,2000,19 (3) :321-340.

14. C. Qiang. Advanced Econometrics and Stata Applications [M]. Beijing: China Higher Education Press, 2010:146-18. 